\title{
BALANÇO DE NUTRIENTES NA PRODUÇÃO DE MUDAS CÍTRICAS CULTIVADAS EM SUBSTRATO ${ }^{1}$
}

\author{
PAULO ROBERTO RONCHINI BOAVENTURA², JOSÉ ANTÔNIO QUAGGIO³, MÔNICA FERREIRA ABREU², \\ ONDINO CLEANTE BATAGLIA ${ }^{3}$
}

\begin{abstract}
RESUMO - A formação de mudas cítricas livres das principais doenças da citricultura e com certificação de origem faz parte da estratégia do setor para manter a continuidade e a competitividade do agronegócio citrícola brasileiro. As normas atuais de defesa sanitária vegetal do Estado de São Paulo determinam que a produção de mudas cítricas certificadas deve ser feita em ambiente protegido por tela à prova de insetos vetores e cultivadas em contêineres com substrato esterilizado. Já existe grande número de empresas produzindo mudas nestas condições, contudo não existem recomendações de doses e formas de manejo de fertilizantes. O ensaio foi conduzido num viveiro comercial, utilizando dois porta-enxertos e dois sistemas de adubação: fertirrigação e fertilizantes de liberação lenta. O período experimental compreendeu desde o transplante das mudas para os contêineres até a poda de formação das mudas, num total de 250 dias, com coletas mensais de plantas e semanais de solução. Os tratamentos foram arranjados no esquema fatorial 2 × 2 × 8, com quatro repetições. Os resultados mostraram que existe tanto imobilização como liberação de nutrientes no substrato, os quais podem superar as perdas por lixiviação. Os balanços entre as quantidades de nutrientes aplicadas e os valores recuperados foram satisfatórios, apesar de não serem exatos devido às fontes de erros que começam na amostragem de volumes de solução por período longo até erros analíticos em laboratório. As perdas de N, Pe K por lixiviação foram, respectivamente, de 8; 12 e 26\% para a fertirrigação e 7; 10; 56\%, para os fertilizantes de liberação lenta, portanto próximas, com exceção do potássio, cujas doses aplicadas foram diferentes entre os sistemas de manejo. Da mesma forma, as quantidades de nutrientes absorvidos também foram semelhantes, com exceções do potássio, manganês e zinco. Isso mostra que a estratégia de seleção do sistema de adubação deve considerar principalmente a questão dos custos dos fertilizantes, pois a principal vantagem apontada para os fertilizantes de liberação lenta, que é diminuir as perdas por lixiviação, não foi observada nesse estudo.
\end{abstract}

Termos para indexação: substrato, perdas de nutrientes.

\section{NUTRIENT BALANCE FOR CITRUS NURSERIES PRODUCTION IN SUBSTRATE UNDER SCREEN-HOUSE}

\begin{abstract}
The production of healthy and vigorous nursery trees in protected environment is the strategy adopted by Brasilian citrus industry to avoid diseases propagation and to improve citrus grove efficiency. A mandatory program for citrus nursery trees certification was established, in the State of São Paulo in 2001, which determine that the nurseries must be produced in pathogen free substrate under screen-house conditions. There are little scientific information on nutrient demand, fertilizer sources and management to advise this program. This project was set up in order to determine nutrient balance for Valencia sweet orange nurseries production, on two rootstocks (Rangpur lime and Swingle citrumelo) using two fertilizer management programs (fertirrigation and slow release fertilizers). The demands of nutrient were evaluated monthly, summing up 250 days. The treatments were arranged in a $2 \times 2 \times 8$ factorial experiment with four replications. The results showed that substrate have both sink and source effects on nutrient availability to nurseries. The N, K e P losses by leaching were respectively of 8,26 and $12 \%$ when the nutrient was applied by fertirrigation and respectively of 7,56 and 10\% for slow release fertilizers. Thus, the advantage of slow release fertilizers to decrease nutrient losses by leaching in relation to fertirrigation was not observed in citrus nursery production in screen-house.
\end{abstract}

Index terms: screen house, substrate, nutrient losses and balance

\section{INTRODUÇÃO}

Muda cítrica produzida em ambiente protegido e com tecnologia moderna é o início de uma nova citricultura, mais eficiente e capaz de garantir a continuidade, a competitividade e o crescimento do agronegócio citrícola brasileiro. Mudas com sanidade comprovada e comercializadas com certificado de origem têm viabilizado a produção de laranjas, principalmente em regiões paulistas duramente afetadas por doenças limitantes, como a Clorose Variegada dos Cítrus (CVC) e o Cancro-Cítrico. Essas mudas estão sendo produzidas em substratos livres de patógenos de solo, o que evita a disseminação de outras doenças, como a gomose e os nematóides, igualmente limitantes à produção citrícola.

Segundo Castle \& Ferguson (1982), a produção de mudas cítricas em ambiente protegido utilizando substratos iniciou-se na Flórida-USA, no final dos anos setenta. A extração de nutrientes por mudas cítricas cultivadas no campo e em substrato foi medida por Castle \& Rouse (1990) em quatro viveiros comerciais da Flórida - EUA, os quais constataram que, apesar de as doses de nutrientes aplicadas serem praticamente as mesmas nos dois sistemas, a extração de nutrientes por muda no campo é quase o triplo daquelas produzidas em substratos, as quais, para N, P e K, extraíram, respectivamente: 0,7;
0,1 e $0,5 \mathrm{~g}$ por planta. Esses valores são muito inferiores aos encontrados por Bernardi (1999), de 1,4; 0,11 e 1,89 g por planta, respectivamente, para os mesmos nutrientes, em ensaio conduzido nas condições do Estado de São Paulo, o que demonstra grande disparidade entre os resultados.

Maust \& Williamson (1994) testaram concentrações de N variando de 0 a $200 \mathrm{mg} \mathrm{L}^{-1}$ e determinaram a concentração de nitrogênio de $19 \mathrm{mg} \mathrm{L}^{-1}$ na solução nutritiva como ideal para o desenvolvimento de mudas cítricas crescidas em areia lavada. Eles comentaram ainda que as doses recomendadas para substratos são diferentes daquelas recomendadas para solução nutritiva, pois recomendam a dose de 250 $\mathrm{mg} \mathrm{L}^{-1}$ de $\mathrm{N}$, para substrato de casca de pínus e vermiculita, todo aplicado via fertirrigação em viveiros da África do Sul.

Williamson \& Castle (1989) verificaram que as doses de nitrogênio usadas por produtores da Flórida-USA, para mudas em substratos, variam de 200 a $400 \mathrm{mg} \mathrm{L}^{-1}$, dependendo da freqüência das aplicações, que, apesar da grande amplitude, são doses mais próximas que as obtidas por Mattos Júnior et al. (2001) com plântulas de limãocravo crescidas em tubetes e também daquelas usadas por produtores na África do Sul (Maust \& Williamson,1994).

Essas diferenças entre os resultados experimentais podem estar relacionados com diferenças no tamanho dos recipientes e perdas

\footnotetext{
${ }^{1}$ (Trabalho 113/2003). Recebido: 04/09/2003. Aceito para publicação: 29/07/2004.

${ }^{2}$ Parte da Dissertação de Mestrado do autor no Curso de Gestão de Recursos Agroambientais do Instituto Agronômico - Centro de Solos e Recursos Agroambientais; Av. Barão de Itapura 1481; Caixa Postal 28 13020-970, Campinas SP.

${ }^{3}$ Instituto Agronômico- Centro Centro de Solos e Recursos Agroambientais; Av. Barão de Itapura 1481; Caixa Postal 28 13020-970, Campinas SP. Bolsistas do CNPq. E-mail: quaggio@iac.sp.gov.br; monica@iac.sp.gov.br; ondino@iac.sp.gov.br
} 
de nutrientes por lixiviação ou volatilização de amônia, no caso do nitrogênio. Castle \& Rouse (1990) verificaram que as quantidades de nutrientes absorvidas por mudas cítricas eram de apenas 5 a $20 \%$ do total de nutrientes aplicados, sendo que as mudas produzidas em contêineres perdem mais nutrientes do que as crescidas no campo, o que demonstra grande potencial de perdas de nutrientes por lixiviação.

De modo geral, as perdas de nutrientes nos contêineres estão muito associadas ao manejo da irrigação e de nutrientes que podem ser aplicados através de fertilizantes sólidos solúveis ou de liberação lenta. Por outro lado, experimentos recentes conduzidos em viveiros de mudas cítricas no Estado de São Paulo mostram que o manejo da água para otimizar a qualidade da muda cítrica deve ser feito para repor $125 \%$ da água necessária para saturar o recipiente, mostrando que é interessante para o manejo dessas mudas que ocorra lixiviação para reduzir o excesso de sais presentes (Olic et al., 2001).

As pesquisas até agora conduzidas são ainda limitadas, havendo pouca informação disponível na literatura sobre demandas por nutrientes para essas plantas e informações científicas para o diagnóstico de desordens nutricionais e interpretação de resultados de análise química de substratos, capazes de orientar o melhor manejo nutricional, melhor aproveitamento dos nutrientes aplicados e qualidade dessas mudas.

Dentro desse contexto o presente trabalho foi planejado com os objetivos de se estudar as perdas de nutrientes na produção de mudas cítricas, em dois porta-enxertos, cultivadas em substrato em ambiente protegido, comparando-se dois sistemas de manejo da fertilização, através de fertirrigação e fertilizantes de liberação lenta.

\section{MATERIAL E MÉTODOS}

O experimento foi conduzido em viveiro comercial em Conchal, principal região produtora de mudas cítricas do Estado de São Paulo. Os porta-enxertos utilizados foram o Limão cravo e Citromelo Swingle , os quais, além de serem amplamente utilizados na citricultura brasileira, têm hábitos distintos de crescimento no viveiro. A variedade de copa utilizada foi a "Valência".

Utilizaram-se plântulas selecionadas de porta-enxertos com 90 dias de idade e cerca de $18 \mathrm{~cm}$ de altura, que estavam sendo produzidos em tubetes e foram transplantados para contêineres, com capacidade de $5000 \mathrm{~cm}^{3}$. Como meio de crescimento das mudas, foi empregado um substrato comercial constituído por casca de pínus compostada e vermiculita, com densidade de $500 \mathrm{~kg} \mathrm{~m}^{-3} \mathrm{e}$ capacidade de retenção de água de $150 \%$. O pH foi corrigido para o valor 6,0 , mediante aplicação de calcário dolomítico, e houve também enriquecimento inicial com $\mathrm{P}$ utilizando o superfosfato simples em dose suficiente para elevar o P-resina para o valor $100 \mathrm{mg} \mathrm{dm}^{-3}$.

Os tratamentos foram constituídos por dois porta-enxertos (Limão-cravo e Citromelo Swingle); dois sistemas de manejo (Fertirrigação e fertilizantes de liberação lenta) e oito épocas de amostragem das plantas, sendo os ensaios arranjados num esquema fatorial $2 \times 2 \times 8$, com quatro repetições. As parcelas foram constituídas inicialmente por 156 mudas, sendo coletadas dez em cada época de amostragem para as avaliações dos parâmetros biométricos do crescimento de planta e absorção dos nutrientes.

$\mathrm{Na}$ fertirrigação, os nutrientes foram aplicados através de solução nutritiva, com a seguinte composição final, em mg L $\mathrm{L}^{-1}: \mathrm{N}=$ $196 ; \mathrm{P}=39 ; \mathrm{K}=187 ; \mathrm{Ca}=142 ; \mathrm{Mg}=45 ; \mathrm{S}=55 ; \mathrm{B}=0,51 ; \mathrm{Cu}=0,13 ; \mathrm{Fe}$ $=1,8 ; \mathrm{Mn}=0,54 ; \mathrm{Zn}=0,23, \mathrm{e} \mathrm{Mo}=0,10$ e Condutividade elétrica $(\mathrm{CE})$ de $2,0 \mathrm{dS} \mathrm{m}^{-1}$. O preparo dessa solução foi feito segundo Furlani (1998). Realizou-se fertirrigação em três aplicações semanais (segundas, quartas e sextas-feiras), aplicando-se um volume de $250 \mathrm{ml}$ de solução nutritiva por planta, $750 \mathrm{ml}$ semanalmente.

No manejo com fertilizante de liberação lenta, utilizou-se um produto comercial, com formulação N, P e K 2204 08, muito usado pelos produtores de mudas cítricas, na proporção de $2,4 \mathrm{~kg}$ de fertilizante para cada metro cúbico de substrato, misturados com betoneira. A irrigação foi realizada em três aplicações semanais (segundas, quartas e sextas-feiras), aplicando-se o mesmo volume total de água utilizado na fertirrigação. Após 60 dias da enxertia, as plantas mantidas com esse sistema de manejo começaram a apresentar sintomas generalizados de deficiência de nitrogênio e retardamento de crescimento. Foram aplicadas, então, adubações suplementares com


${ }^{3} \mathrm{de} \mathrm{Ca}$, juntamente com os micronutrientes da solução nutritiva usada no manejo da fertirrigação. Essa solução foi aplicada três vezes por semana, no volume de $250 \mathrm{ml}$ por sacola, $750 \mathrm{ml}$ semanalmente, em substituição à água de irrigação.

A amostragem de planta para avaliar o acúmulo de nutrientes foi feita mensalmente, desmanchando-se dez contêineres por parcela. As amostras eram separadas em raízes, caule e folhas, para a determinação da matéria seca acumulada. Após a lavagem, secagem e moagem, essas amostras foram analisadas para os teores totais de macro e micronutrientes, segundo os métodos descritos por Bataglia et al. (1983). Simultaneamente, amostras de substrato dos contêineres eram colhidas, e após a secagem e moagem foram também analisadas pelos procedimentos descritos por Bataglia et al. (1983) para as determinações dos teores totais de macro e micronutrientes.

As amostragens da solução lixiviada através dos contêineres foram feitas semanalmente para um conjunto de quatro plantas por repetição, totalizando 28 semanas de coleta de amostras no transcorrer do experimento. Para tanto, quatro plantas, em posições diferentes dentro de cada parcela, foram colocadas dentro de vasos plásticos, perfurados na parte basal e com fundo falso, capaz de armazenar as soluções percoladas das três irrigações ou fertirrigações semanais de cada uma das quatro plantas. Posteriormente, as amostras de cada vaso foram misturadas, homogeneizadas, tendo seu volume determinado no viveiro com o auxílio de uma proveta. Dessa forma, era obtido o volume lixiviado por planta em cada parcela. Uma alíquota por repetição dessa solução era encaminhada ao laboratório para as determinações de $\mathrm{pH}$, condutividade elétrica e nitrogênio mineral $\left(\mathrm{NO}_{3}\right.$ e $\left.\mathrm{NH}_{4}\right)$, pelos métodos descritos em Raij et al. (2001). Os demais nutrientes foram determinados por leitura direta em espectrômetro de plasma de argônio, enquanto o íon cloreto foi determinado por eletrodo seletivo em potenciômetro calibrado.

O consumo de água perdida por evaporação foi medido semanalmente, subtraindo-se do volume total de água perdida o volume de solução lixiviada. A perda total de água foi obtida por diferença da massa dos vasos no início e final da semana, acrescentando-se a essa diferença o volume de solução de fertirrigação ou de água de irrigação aplicada durante a semana.

As análises estatísticas de todas as variáveis estudadas foram baseadas nas análises de variância e de regressão, realizadas através do programa de estatística Minitab (Minitab, 2000).

\section{RESULTADOS E DISCUSSÃO}

\section{Volume do lixiviado e condutividade elétrica}

A dinâmica de nutrientes na nutrição de plantas cultivadas em contêineres com substrato está muito ligada ao manejo de água ou controle da irrigação. Nesse tipo de cultivo, há tendência de acúmulo de sais no substrato, principalmente nas épocas mais quentes, quando aumentam as perdas de água por evaporação. Por essa razão, o trabalho de Olic et al. (2001) mostrou que, para otimizar a qualidade das mudas cítricas, o manejo da água deve ser feito para repor de 100 a $125 \%$ da água perdida por evapotranspiração para se garantir a lavagem do excesso de sais presentes.

No presente trabalho, o volume de solução lixiviada foi significativamente $(\mathrm{p}<0,01)$ superior no manejo com fertilizante de liberação lenta, em todas as fases do crescimento das mudas (Figura 1). Aos 250 dias após o transplante, que corresponde à poda de formatura ou quando a muda está pronta para ir para o campo, 
TABELA 1 - Perdas de solução e de nutrientes por contêiner, nos dois sistemas de manejo da adubação, para a média dos porta-enxertos.

\begin{tabular}{|c|c|c|c|c|c|c|c|c|c|c|c|c|c|c|c|}
\hline $\begin{array}{l}\text { Dias após } \\
\text { transplante }\end{array}$ & $\begin{array}{l}\text { Soluçãa } \\
\text { (1) }\end{array}$ & NH4 & NO3 & $\mathrm{N}$ total & $\mathbf{P}$ & $\mathbf{K}$ & $\mathrm{Ca}$ & $\begin{array}{c}\text { Mg } \\
\text { mg por }\end{array}$ & $\begin{array}{c}\mathrm{S} \\
\text { contêine }\end{array}$ & $\mathbf{N a}$ & B & $\mathrm{Cu}$ & $\mathbf{F e}$ & Mn & Zn \\
\hline & & \multicolumn{14}{|c|}{ Fertirrigação } \\
\hline 35 & 624,3 & 4,3 & 50,0 & 54,3 & 12,3 & 81,8 & 233,3 & 93,3 & 126,3 & 9,4 & 0,23 & 0,79 & 0,36 & 0,17 & 0,07 \\
\hline 70 & 329,4 & 3,8 & 23,0 & 26,8 & 9,5 & 78,7 & 112,1 & 39,2 & 43,0 & 3,7 & 0,17 & 0,13 & 0,34 & 0,15 & 0,05 \\
\hline 100 & 440,1 & 9,2 & 43,2 & 52,4 & 18,1 & 124,9 & 155,5 & 54,7 & 50,4 & 3,6 & 0,28 & 0,24 & 0,50 & 0,29 & 0,08 \\
\hline 160 & 761,0 & 8,2 & 88,6 & 96,8 & 23,5 & 268,6 & 400,8 & 165,7 & 177,6 & 13,4 & 0,48 & 0,31 & 0,71 & 0,43 & 0,21 \\
\hline 190 & 622,3 & 4,5 & 48,1 & 52,6 & 16,1 & 207,0 & 260,1 & 112,7 & 131,1 & 10,4 & 0,33 & 0,17 & 0,47 & 0,29 & 0,33 \\
\hline 220 & 839,1 & 5,3 & 56,1 & 61,4 & 20,3 & 281,5 & 369,8 & 162,6 & 159,0 & 16,2 & 0,43 & 0,19 & 0,58 & 0,40 & 0,36 \\
\hline 250 & 329,5 & 5,5 & 20,2 & 25,7 & 12,8 & 110,8 & 111,4 & 41,7 & 42,8 & 3,9 & 0,22 & 0,16 & 0,37 & 0,24 & 0,26 \\
\hline Totais & 3945,7 & 40,8 & 329,3 & 370,1 & 112,5 & 1153,3 & 1643,0 & 670,0 & 730,2 & 60,6 & 2,15 & 1,99 & 3,32 & 1,97 & 1,35 \\
\hline \multicolumn{16}{|c|}{ Liberação Lenta } \\
\hline 35 & 749,5 & 4,7 & 67,2 & 71,6 & 14,9 & 116,1 & 579,0 & $314,3^{3}$ & 347,3 & 14,7 & 0,16 & 0,09 & 0,16 & 5,02 & 0,20 \\
\hline 70 & 345,3 & 1,0 & 18,4 & 19,4 & 3,4 & 42,7 & 122,6 & 59,1 & 72,9 & 4,1 & 0,04 & 0,02 & 0,02 & 1,13 & 0,05 \\
\hline 100 & 567,6 & 1,0 & 28,4 & 29,4 & 3,5 & 69,4 & 89,4 & 47,6 & 63,8 & 3,7 & 0,03 & 0,02 & 0,02 & 0,75 & 0,04 \\
\hline 160 & 861,0 & 5,5 & 75,6 & 81,1 & 8,2 & 104,2 & 361,8 & 181,5 & 130,0 & 11,8 & 0,08 & 0,08 & 0,06 & 2,53 & 0,35 \\
\hline 190 & 641,8 & 4,2 & 37,7 & 42,0 & 6,7 & 82,2 & 352,5 & 156,6 & 177,7 & 9,2 & 0,07 & 0,07 & 0,05 & 2,32 & 0,65 \\
\hline 220 & 748,4 & 4,4 & 47,6 & 52,0 & 6,8 & 90,2 & 430,3 & 198,9 & 183,0 & 13,5 & 0,23 & 0,10 & 0,37 & 3,08 & 1,13 \\
\hline 250 & 343,1 & 3,2 & 18,8 & 22,0 & 2,1 & 29,4 & 177,6 & 49,7 & 38,2 & 4,3 & 0,21 & 0,27 & 0,34 & 1,01 & 0,81 \\
\hline Totais & 4256,8 & 24,1 & 293,5 & 317,4 & 45,6 & 534,1 & 2113,1 & 1007,7 & 1012,9 & 61,2 & $\mathbf{0 , 8 1}$ & 0,64 & 1,02 & 15,83 & 3,23 \\
\hline
\end{tabular}

(1) Volume de solução lixiviada, $\mathrm{ml}$ por contêiner

observou-se que, no manejo com fertirrigação, o volume total de solução perdida atingiu $3.945,7 \mathrm{ml}$ por contêiner, enquanto com fertilizantes de liberação lenta, essa perda foi maior, atingindo $4.256,8$ $\mathrm{ml}$ por contêiner (Tabela 1). Parte dessa diferença pode ser explicada pelo menor crescimento das mudas, notadamente no final do ciclo de produção, no sistema de liberação lenta, conforme os resultados de crescimento das plantas apresentados por Boaventura (2003). Como a quantidade de substrato no contêiner era de $5.000 \mathrm{~cm}^{-3}$, pode-se considerar que um volume quase equivalente de água foi perdido por lixiviação, desde o transplante do cavalinho até o final da fase de produção da muda cítrica, cuja duração média é cerca de 8 meses.

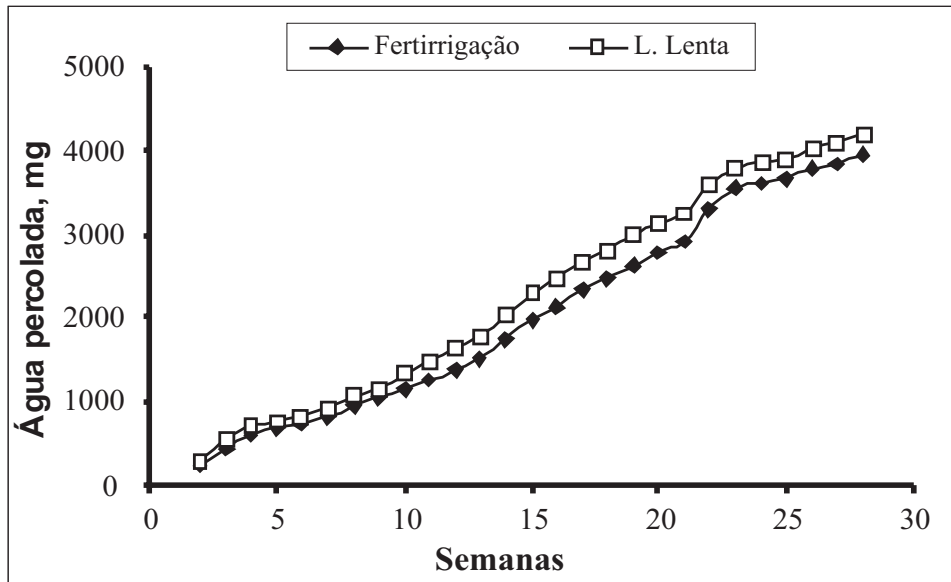

FIGURA 1 - Perda de água por percolação, acumulada em 28 coletas semanais, em dois sistemas de manejo da nutrição.

Esse volume é responsável pela perda total de nutrientes por lixiviação e é inversamente proporcional ao volume de água perdido por evapotranspiração das mudas, conforme mostra a Figura 2. Observase ainda, nessa figura, que os porta-enxertos de limão-cravo e citromelo Swingle tiveram praticamente o mesmo comportamento de consumo de água. De modo geral, as perdas de água por evapotranspiração, em ordem de grandeza, representam o dobro do volume perdido por lixiviação e, nas épocas mais quentes, ultrapassam o volume semanal de $750 \mathrm{ml}$ de água, aplicado na fertirrigação ou irrigação. Isso demonstra grande potencial para o acúmulo de sais nesse sistema de produção de mudas, que pode explicar os resultados de Olic et al. (2001), que

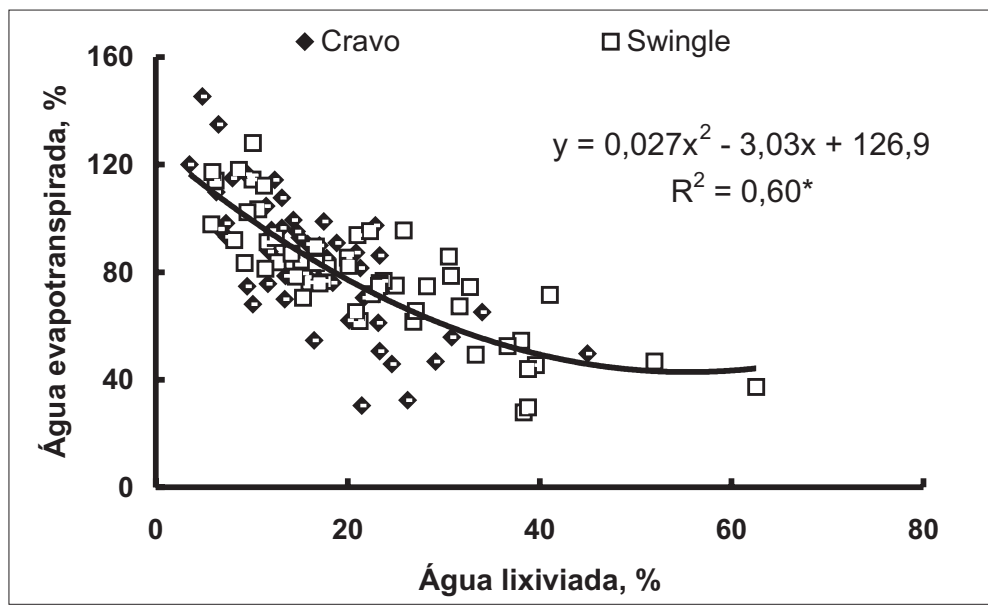

FIGURA 2 - Correlação entre as porcentagens de água perdida por evapotranspiração e por percolação, para a média de dois porta-enxertos.

observaram melhor crescimento das mudas quando o volume de água de irrigação supria $125 \%$ da água perdida do contêiner.

Os valores da condutividade elétrica (CE) da Figura 3 mostram que há acúmulo de sais em quase todo o período de crescimento das mudas, pois, no caso da fertirrigação, a solução usada possuía $\mathrm{CE}=2,0$ $\mathrm{dS} \mathrm{m} \mathrm{m}^{-1}$ na Figura 3a, nota-se que, para esse sistema de manejo, a CE variou na média dos porta-enxertos entre 2,0 e 5,0 dS m${ }^{-1}$. Existe correlação estreita entre os valores de CE e o somatório de íons na solução lixiviada através dos contêineres, a qual pode ser usada para estimar as perdas de nutrientes diretamente no viveiro, usando-se apenas um condutivímetro. Entre os cátions, as concentrações de Ca e $\mathrm{Mg}$ foram as mais correlacionadas com a CE, respectivamente, $\mathrm{r}=0,90^{* *}$ e r=0,78*. Entre os ânions, o $\mathrm{SO}_{4}$ foi o que mais se correlacionou com a CE $(r=0,68 *)$. As concentrações mais elevadas de Ca e $\mathrm{Mg}$ na solução lixiviada de contêineres com fertilizantes de liberação lenta em relação à fertirrigação podem explicar os valores maiores de CE e menores de pH (Tabela 2). Desse modo, o manejo com liberação lenta tem maior potencial de acidificação e de provocar estresse salino nas mudas cítricas, devido à maior amplitude observada nos valores de CE (Figura 3a). Da mesma maneira, a CE da solução lixiviada através dos contêineres cultivados com limão-cravo apresentou maior amplitude de variação em relação ao citromelo Swingle, porém ambos ajustaram-se no mesmo modelo estabelecido entre CE e ao somatório de íons (Figura 3b). 

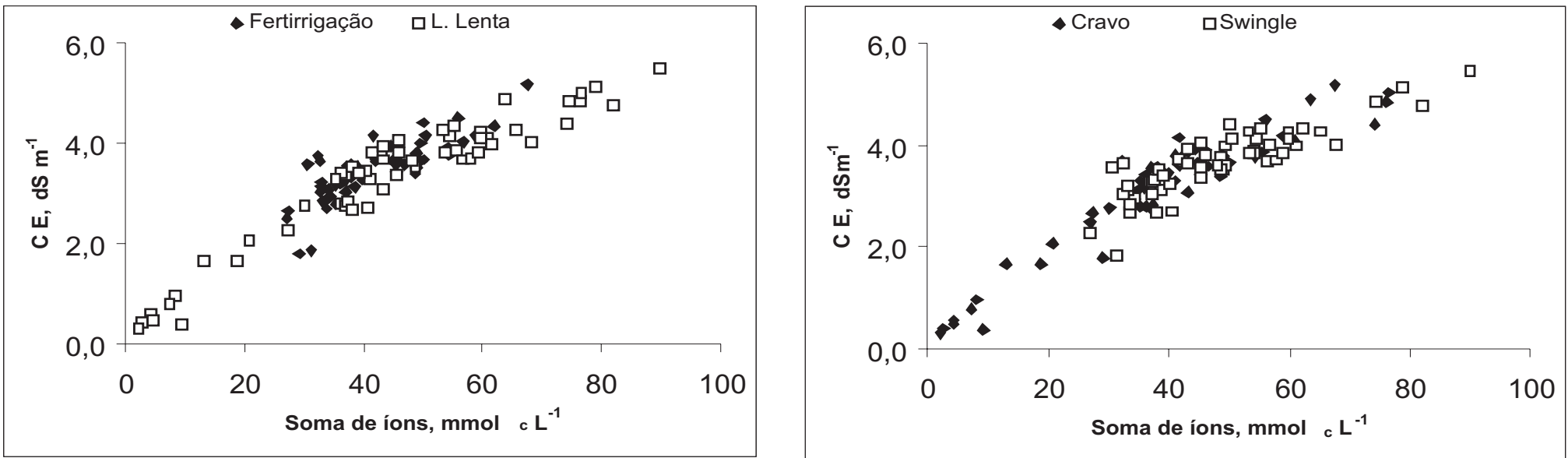

FIGURA 3 - Relações entre a condutividade elétrica e o somatório de íons para a média de sistemas de manejo (a) e médias dos porta-enxertos (b)

\section{Perdas de nutrientes}

As concentrações dos nutrientes no lixiviado variam muito ao longo do período de crescimento das mudas, porém não foram observadas correlações significativas entre essas concentrações e o volume de solução lixiviada para os diferentes sistemas de manejo estudados (Tabela 2). Essa variabilidade nas concentrações dos nutrientes ao longo do crescimento foi observada também por Broschat (1995) com plantas ornamentais cultivadas em contêineres com substrato composto por casca de pínus, turfa e areia.

No caso da fertirrigação, é interessante observar que a concentração de alguns nutrientes, como $\mathrm{Ca}, \mathrm{Mg}, \mathrm{K}, \mathrm{Cu}, \mathrm{S}$ e $\mathrm{Zn}$, aumentam, enquanto outros, como o $\mathrm{N}$ e Fe, diminuem a concentração em relação à solução original de fertirrigação. Isso demonstra que existem

TABELA 2 - Volume de solução e concentração de nutrientes, em várias épocas de amostragem, para dois sistemas de manejo da adubação de mudas cítricas cultivadas em contêineres .

\begin{tabular}{|c|c|c|c|c|c|c|c|c|c|c|c|c|c|c|c|c|c|}
\hline $\begin{array}{l}\text { Dias após } \\
\text { transplante }\end{array}$ & $\begin{array}{c}\text { Vol. de } \\
\text { ml }\end{array}$ & $\begin{array}{c}\text { solução } \\
\%\end{array}$ & pH & $\begin{array}{l}\text { C.E. } \\
\text { dS m }^{-1}\end{array}$ & $\mathbf{N a}$ & $\mathbf{K}$ & NH4 & NO3 & $\begin{array}{c}B \\
\mathbf{m g ~ L}^{-1}\end{array}$ & Ca & $\mathbf{C u}$ & $\mathbf{F e}$ & Mg & Mn & $\mathbf{P}$ & $\mathbf{S}$ & Zn \\
\hline & \multicolumn{17}{|c|}{ Fertirrigação } \\
\hline 35 & 148,0 & 19,7 & 5,3 & 2,5 & 14,2 & 92,1 & 7,3 & 79,7 & $0,4^{\circ}$ & 349,0 & 1,7 & 0,5 & 143,0 & 0,3 & 23,0 & 195,1 & 0,1 \\
\hline 70 & 101,9 & 13,6 & 4,9 & 3,3 & 12,8 & 237,1 & 10,7 & 74,6 & 0,5 & 357,2 & 0,4 & 1,0 & 130,2 & 0,4 & 27,3 & 150,1 & 0,2 \\
\hline 100 & 110,0 & 14,7 & 4,8 & 3,3 & 8,5 & 288,2 & 21,2 & 99,5 & 0,7 & 364,8 & 0,5 & 1,1 & 127,0 & 0,7 & 42,1 & 117,7 & 0,2 \\
\hline 160 & 190,3 & 25,4 & 5,0 & 3,9 & 16,8 & 352,7 & 11,8 & 117,7 & 0,6 & 509,5 & 0,4 & 1,0 & 209,8 & 0,6 & 32,7 & 225,0 & 0,3 \\
\hline 190 & 155,6 & 20,7 & 5,0 & 3,8 & 17,0 & 333,8 & 7,5 & 73,3 & 0,5 & 422,9 & 0,3 & 0,8 & 181,5 & 0,5 & 26,3 & 208,8 & 0,5 \\
\hline 220 & 209,8 & 28,0 & 4,9 & 3,7 & 17,8 & 340,8 & 8,1 & 67,0 & 0,6 & 419,0 & 0,3 & 0,8 & 177,2 & 0,5 & 28,1 & 177,7 & 0,5 \\
\hline 250 & 82,4 & 10,9 & 4,6 & 3,6 & 12,2 & 340,3 & 16,6 & 60,2 & 0,7 & 353,7 & 0,5 & 1,2 & 132,6 & 0,8 & 39,4 & 137,2 & 0,8 \\
\hline \multirow[t]{2}{*}{ Média } & 142,6 & 19,0 & 4,9 & 3,4 & 14,2 & 283,6 & 11,9 & 81,7 & 0,6 & 396,6 & 0,6 & 0,9 & 157,3 & 0,5 & 31,2 & 173,1 & 0,4 \\
\hline & \multicolumn{17}{|c|}{ Liberação Lenta } \\
\hline 35 & 193,7 & 25,8 & 4,5 & 4,4 & 17,8 & 123,3 & 6,2 & 89,8 & 0,2 & 747,9 & 0,1 & 0,2 & 412,8 & 6,2 & 20,9 & 460,0 & 0,3 \\
\hline 70 & 102,7 & 13,7 & 4,9 & 3,2 & 14,1 & 140,1 & 3,3 & 64,2 & 0,1 & 414,0 & 0,1 & 0,1 & 205,2 & 3,7 & 10,5 & 245,2 & 0,2 \\
\hline 100 & 141,9 & 18,9 & 5,3 & 1,6 & 7,1 & 128,3 & 1,9 & 53,9 & 0,1 & 186,2 & 0,0 & 0,0 & 96,5 & 1,6 & 6,8 & 129,1 & 0,1 \\
\hline 160 & 215,3 & 27,6 & 4,9 & 2,8 & 13,4 & 115,6 & 6,5 & 88,6 & 0,1 & 389,9 & 0,1 & 0,1 & 196,8 & 2,7 & 9,2 & 250,6 & 0,4 \\
\hline 190 & 160,5 & 21,4 & 4,5 & 3,6 & 14,0 & 116,6 & 7,7 & 59,5 & 0,1 & 516,9 & 0,1 & 0,1 & 217,4 & 3,3 & 9,7 & 239,7 & 1,1 \\
\hline 220 & 187,1 & 24,9 & 4,5 & 3,9 & 16,3 & 109,3 & 6,5 & 59,7 & 0,4 & 540,8 & 0,2 & 0,6 & 231,1 & 3,7 & 8,2 & 210,4 & 1,8 \\
\hline 250 & 85,8 & 11,4 & 4,2 & 3,6 & 12,4 & 84,5 & 9,6 & 54,4 & 0,6 & 505,6 & 0,7 & 1,0 & 140,5 & 2,9 & 6,0 & 115,4 & 2,3 \\
\hline Média & 155,3 & 20,5 & 4,7 & 3,3 & 13,6 & 116,8 & 6,0 & 67,2 & 0,2 & 471,6 & 0,2 & 0,3 & 214,3 & 3,4 & 10,2 & 235,8 & $\mathbf{0 , 9}$ \\
\hline \multicolumn{18}{|l|}{ Teste F } \\
\hline Época & $* *$ & $* *$ & $* *$ & $* *$ & $* *$ & $* *$ & $* *$ & $* *$ & $* *$ & $* *$ & $* *$ & $* *$ & $* *$ & $* *$ & $* *$ & $* *$ & $* *$ \\
\hline Manejo & ns & ns & $* *$ & $*$ & ns & $* *$ & $* *$ & $* *$ & $* *$ & $* *$ & $* *$ & $* *$ & $* *$ & $* *$ & $* *$ & $* *$ & $* *$ \\
\hline
\end{tabular}

$(1) * *$ Significativo $(p<0,01), *$ Significativo $(p<0,05)$ e $n s=$ não significativo
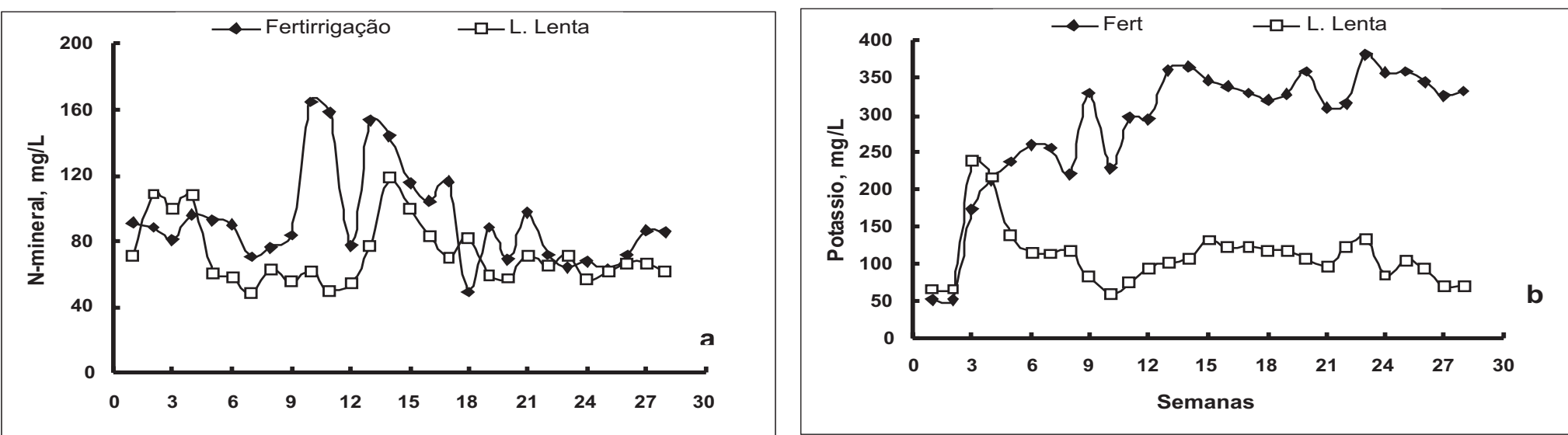

FIGURA 4 - Variações nas concentrações de $\mathrm{N}$ mineral $\left(\mathrm{NO}_{3}+\mathrm{NH}_{4}\right)$ (a) e de $\mathrm{K}$ (b) durante 28 semanas de coleta de lixiviado dos contêineres. 
TABELA 3 - Balanço de nutrientes para a produção de mudas cítricas em ambiente protegido, em dois sistemas de manejo da adubação.

\begin{tabular}{|c|c|c|c|c|c|c|c|c|c|c|c|}
\hline \multirow{2}{*}{$\begin{array}{l}\text { 10tal de } \\
\text { Nutriente }\end{array}$} & $\mathrm{N}$ & $\mathrm{K}$ & $\mathrm{P}$ & $\mathrm{Ca}$ & $\mathrm{Mg}$ & $\mathrm{S}$ & $\mathrm{B}$ & $\mathrm{Cu}$ & $\mathrm{Fe}$ & $\mathrm{Mn}$ & $\mathrm{Zn}$ \\
\hline & \multicolumn{11}{|c|}{ mg por contêiner } \\
\hline & \multicolumn{11}{|c|}{ Fertirrigação } \\
\hline Aplicado & 4586 & 4375 & 917 & 3223 & 1043 & 1297 & 12,2 & 6,4 & 42,1 & 12,6 & 7,5 \\
\hline Absorvido & 1564 & 1013 & 113 & 838 & 95 & 124 & 2,1 & 1,3 & 15,2 & 3,4 & 1,5 \\
\hline Lixiviado & 370 & 1153 & 113 & 1643 & 670 & 730 & 2,1 & 3,3 & 3,3 & 2,0 & 2,1 \\
\hline Imobilizado no substrato $^{(1)}$ & 3689 & 1511 & 861 & -293 & 260 & 228 & $-11,9$ & 151,0 & 3,8 & 63,4 & 29,4 \\
\hline Uso de nutriente, $\%$ & 34 & 23 & 12 & 26 & 9 & $9+$ & 17 & 20 & 36 & 27 & 20 \\
\hline Lixiviação, \% & 8 & 26 & 12 & 51 & 65 & 56 & 17 & 51 & 8 & 16 & 28 \\
\hline \multirow[t]{2}{*}{ Balanço $^{(2)}$} & -1037 & +698 & -169 & +450 & +18 & +216 & $-4,0$ & $-149,2$ & $+19,9$ & $-56,1$ & $-25,5$ \\
\hline & & \multicolumn{10}{|c|}{ Liberação lenta } \\
\hline Aplicado & 4697 & 950 & 480 & 3648 & 120 & 360 & 5,9 & 7,6 & 132,2 & 15,6 & 7,6 \\
\hline Absorvido & 1508 & 726 & 115 & 755 & 101 & 136 & 1,7 & 1,1 & 15,8 & 26,2 & 3,0 \\
\hline Lixiviado & 317 & 534 & 46 & 2113 & 1008 & 1013 & 0,8 & 0,6 & 1,0 & 15,8 & 3,2 \\
\hline Imobilizado no substrato $^{(1)}$ & -1479 & -1245 & 390 & -666 & -894 & -260 & $-23,4$ & 18,8 & 9,1 & $-54,1$ & 40,1 \\
\hline Uso de nutriente, $\%$ & 32 & 76 & 24 & 21 & 85 & 38 & 29 & 14 & 12 & 167 & 39 \\
\hline Lixiviação, \% & 7 & 56 & 10 & 58 & 840 & 281 & 14 & 8 & 1 & 101 & 42 \\
\hline Balanço ${ }^{(2)}$ & +1393 & -1555 & -71 & +114 & -95 & -1049 & $-20,0$ & $-12,9$ & $+106,3$ & $-79,9$ & $-38,8$ \\
\hline
\end{tabular}

(1) Teor total final menos o teor inicial do nutriente no substrato. (2) Sinal negativo significa imobilização do nutriente no substrato, enquanto o sinal positivo significa liberação.

tanto interações que levam à imobilização como à liberação desses nutrientes no substrato. No caso do N, a imobilização no substrato levou à perda do nutriente muito superior à observada por lixiviação (Tabela 2).

$\mathrm{Na}$ Figura 4, observa-se que existem diferenças significativas nas concentrações de $\mathrm{N}$ total $\left(\mathrm{NH}_{4}+\mathrm{NO}_{3}\right)$ e de potássio entre os sistemas de manejo da nutrição nas diferentes épocas de amostragem. É interessante notar que o fertilizante de liberação lenta proporcionou perdas semelhantes ou significativamente superiores de $\mathrm{N}$ e $\mathrm{K}$, nas primeiras épocas de amostragem, em relação ao manejo com fertirrigação, demonstrando que, nas condições desse experimento, as vantagens normalmente atribuídas pelos fabricantes desse tipo de fertilizante, de reduzir as perdas de nutrientes por lixiviação, não tiveram efeito. Resultados semelhantes foram obtidos com plantas ornamentais por Hershey \& Paul (1982) que, durante 11 semanas, observaram perdas ao redor de $27 \%$ da dose média de $\mathrm{N}$ aplicada tanto para os fertilizantes de liberação lenta como para a fertirrigação com fertilizantes solúveis. No presente ensaio, considerando-se o ciclo total de 28 semanas, as perdas de $\mathrm{N}$ foram, respectivamente, de $27 \%$ e $30 \%$ do total de $\mathrm{N}$ aplicado, para fertilizantes de liberação lenta e fertirrigação, portanto próximo dos valores obtidos por Hershey \& Paul (1982) (Tabela 3). Cox (1993) e Broschat (1995) também não observaram redução nas perdas de $\mathrm{N}$ com o uso de fertilizantes de liberação lenta em plantas ornamentais cultivadas em contêineres com substrato, em períodos de 10 a 12 semanas.

As menores perdas de K observadas na Figura 4b, com o manejo de fertilizantes de liberação lenta, devem-se à menor quantidade aplicada, a qual foi muito próxima à extraída pela muda, e não devido à liberação mais lenta do nutriente pelo fertilizante (Tabela 3). O mesmo ocorreu para o P, pois, com exceção da primeira época de amostragem, as concentrações desse nutriente foram sempre superiores na fertirrigação devido à aplicação do nutriente durante todo o ciclo de crescimento das mudas.

As perdas de $\mathrm{Ca}$ e $\mathrm{Mg}$ foram muito superiores no manejo com fertilizantes de liberação lenta, com efeitos significativos sobre os valores de $\mathrm{pH}$ (Tabelas 1 e 2). Essa maior acidificação provavelmente explica as maiores perdas de alguns micronutrientes, como o B, Zn e Mn, cujas solubilidades aumentam com a acidificação do meio. No caso do Mn, esse aumento exagerado na disponibilidade provocou sintomas típicos de toxicidade do nutriente nas folhas das mudas.

\section{Balanço de nutrientes}

Na Tabela 3, está representado o balanço entre as quantidades dos nutrientes aplicados, absorvidos pela planta, perdidos por lixiviação e as interações com o substrato que, dependendo do nutriente e manejo, pode ser de imobilização (sinais negativos) ou de liberação (sinais positivos). Essas interações foram determinadas pela diferença dos resultados dos teores totais de nutrientes no substrato, no final, menos o inicial do ensaio (dados não apresentados).

$\mathrm{O}$ balanço quando negativo significa que as fontes de drenos superaram a dose total do nutriente aplicada, e o inverso ocorreu com o sinal positivo. Observa-se que o fechamento não foi exato devido a inúmeras fontes de erros existentes em todo o processo, desde a coleta das amostras de substrato de solução lixiviada e de plantas até as análises laboratoriais. Porém, para a maioria dos nutrientes e principalmente no manejo com fertirrigação, a recuperação dos nutrientes aplicados foi satisfatória. As maiores discrepâncias foram observadas com o $\mathrm{N}$ e o K, principalmente com o uso de fertilizantes de liberação lenta. Para o N, houve grande diferença entre os sistemas de manejo, pois na fertirrigação ocorreu imobilização, enquanto com fertilizante de liberação lenta houve liberação do nutriente pelo substrato. Cabe ressaltar que, no início do ensaio, no manejo da fertirrigação, a relação $\mathrm{C} / \mathrm{N}$ do substrato era 60:1, enquanto com a adição dos fertilizantes de liberação lenta, ela foi reduzida para 40:1, o que deve ter provocado mineralização e alterações físicas no substrato.

As perdas de N, $\mathrm{P}$ e K por lixiviação foram, respectivamente, de $8 ; 12$ e $26 \%$ para a fertirrigação, que são próximos aos valores observados por Bernardi et al. (2001) que também usaram esse mesmo sistema de manejo. Nota-se ainda que as perdas desses nutrientes, quando foram usados fertilizantes de liberação lenta, foi de $7 ; 10$ e $56 \%$, respectivamente para $\mathrm{N}, \mathrm{P}$ e K, portanto, com exceção do potássio, são próximas às perdas observadas com a fertirrigação. Em razão do comportamento equivalente dos fertilizantes de liberação lenta e da fertirrigação com aqueles solúveis em água, a estratégia de seleção do sistema de adubação deve considerar principalmente os custos dos produtos.

\section{CONCLUSÕES}

1. No manejo com fertirrigação, a recuperação dos nutrientes aplicados foi satisfatória.

2. Para o nitrogênio, houve grande diferença entre os sistemas de manejo, pois na fertirrigação ocorreu imobilização, enquanto com fertilizante de liberação lenta houve liberação do nutriente pelo substrato.

3. As perdas de nutrientes $\mathrm{N}$ e $\mathrm{K}$ por lixiviação foram equivalentes nos sistemas de manejo com fertirrigação ou com fertilizantes de liberação lenta. 


\section{AGRADECIMENTOS}

Os autores agradecem às empresas Eucatex Agro, pelo apoio financeiro, e a Citrograf Mudas, pelo apoio na condução do ensaio

\section{REFERÊNCIAS BIBLIOGRÁFICAS}

BATAGLIA, O. C.; FURLANI, A. M. C.; TEIXEIRA, J. P. F.; FURLANI, P. R.; GALLO, J. R. Métodos de análise química de plantas: Campinas: Instituto Agronômico, 1983. 48p. (Boletim Técnico, 78)

BOAVENTURA, P. S. Demanda de nutrientes por mudas cítricas cultivadas em substrato em ambiente protegido. 2003. $72 \mathrm{f}$. Dissertação (Mestrado) - Instituto Agronômico, Campinas, 2003.

BERNARDI, A.C. de C. Produção em vasos de mudas de cítrus em resposta à adubação NPK em ambiente protegido. 1999. 108f. Tese (Doutorado) - Escola Superior de Agricultura "Luiz de Queiróz", Universidade de São Paulo", Piracicaba, 1999.

BERNARDI, A.C.; CARMELLO, C.A.; CARVALHO, S.A. Growth and nutrient leaching of containerized citrus rootstock due to fertilizations with nitrogen, phosphorus and potassium. In: INTERNATIONAL CONGRESS OF CITRUS NURSERYMEN, 6., 2001, Ribeirão Preto, Proceedings...p. 249-253.

BROSCHAT, T.K. Nitrate, Phosphate, and Potassium leaching from container grown plants fertilized by several methods. HortScience, Alexandria, v.30, n.1, p.74-77, 1995 .

CASTLE, W.S.; FERGUSON, J.J. Current status of greenhouse and container production of citrus nursery trees in Proceedings of the Florida State Horticultural Society. Winter Haven, p. 42-46, 1982.

CASTLE, W.S.; ROUSE, R.E. Total mineral nutrient content of florida citrus nursery plant. Proceedings of the Florida State Horticultural Society, Winter Haven, 103, p. 42-44, 1990.
COX, D.A. Reducing nitrogen leaching-losses from containerized plants: the effectiveness of controlled-release fertilizers. Journal of Plant Nutrition, Monticello, v.16, n.3, p.533-545, 1993.

FURLANI, P.R. Instruções para o cultivo de hortaliças de folhas pela técnica de Hidroponia-NFT. Campinas: Instituto Agronômico, 1998. 30p. (Boletim Técnico, 168).

HERSHEY, D.R.; PAUL, J.L. Leaching losses of nitrogen from pot chrysanthemums with controlled release or liquid fertilization. Science. Hort., v.17, p.145-152, 1982.

MATTOS, D. Jr ; CARVALHO, S.A.; PEDROSO, F.G. Nitrogen fertilization for rangpur lime (Citrus limonia $(\mathrm{L})$, Osb) seedlings grown under screen house environment. In: INTERNATIONAL CONGRESS OF CITRUS NURSERYMEN, 6., 2001, Ribeirão Preto, Proceedings... p. 263-265.

MAUST, B.E.; WILLIAMSON, J.G. Nitrogen nutrition of containerized citrus nursery plants. Journal of the American Society for Horticultural Science, Alexandria, v.119, n.2, p.195-201, 1994.

MINITAB User's guide 2: Data analysis and quality tools. Release 13. State College, 2000. 752p.

OLIC, F.B.; MOURÃO FILHO, F.A.A.; GRAF, C.C.D.; GIRARDI, E.A.; SALVO, J.G.; COELHO, R.D. Vegetative growth of containerized citrus nursery trees subjected to five levels of irrigation. In: INTERNATIONAL CONGRESS OF CITRUS NURSERYMEN, 6 ., 2001, Ribeirão Preto, Proceedings... p. 131-133.

RAIJ, B Van; ANDRADE, J.C.; CANTARELLA, H.; QUAGGIO, J.A. Análise química para avaliação da fertilidade de solos tropicais. Campinas, SP: Instituto Agronômico, 2001. 285p.

WILLIAMSON, J.G.; CASTLE, W.S. A survey of Flórida citrus nursery. Proceedings of the Florida State Horticultural Society. Winter Haven, v.102, p.78-82. 1989. 